\title{
ADSORPTION OF Cr(III) IONS USING LOW-COST MATERIAL AND ASSESSMENT OF WATER QUALITY IN GREYWATER: A SUSTAINABLE APPROACH
}

\author{
R. M. Muthuraman ${ }^{1,}$, A. Murugappan ${ }^{1}$ and B. Soundharajan ${ }^{2}$ \\ ${ }^{1}$ Department of Civil Engineering, Annamalai University, Chidambaram \\ ${ }^{2}$ Department of Civil Engineering, Amrita Vishwa Vidyapeetham, Coimbatore \\ Corresponding Author: rm.muthuraman198711@gmail.com
}

\begin{abstract}
In this study, moringa seed powder was used to remove heavy metals in the solution using the adsorption process. The effect of temperature and $\mathrm{pH}$ on the adsorption efficiency of moringa seeds was evaluated. Moringa seeds were effective in removing chromium and can act as a better sustainable material to remove heavy metals in the solution. The natural low-cost materials are effective in treating the greywater coming out from the households. The low-cost material used in this study to treat the greywater was moringa seed powder. The seed powder, sand and activated carbon were used in a filter bed and the removal efficiency of these materials was calculated at different contact times. The effluent and influent water were compared with World Health Organization (WHO) and Tamilnadu Pollution control board (TNPCB) standards. The effluent water was analyzed for different parameters of water quality which include pH, TDS, TSS, Hardness, Chloride, Sulphate, oil and grease, etc. The utilization of moringa seed powder was effective in enhancing the water quality and complies with the World Health Organization and Tamilnadu Pollution control board standards.
\end{abstract}

Keywords: Moring Seed Powder, Water Quality, World Health Organization, Greywater

RASĀYANJ. Chem., Vol. 14, No.3, 2021

\section{INTRODUCTION}

In view of climate change and high population growth, the demand for water rises day by day and human beings are facing scarcity in water. ${ }^{1-3}$ This scarcity of resources puts more stress on the policymakers to create efficient water policies for nations to treat wastewater from industries and households. Temporary policies were in force on several nations around the globe to satisfy the current water demands. Due to the emergence of various industries, toxic metals coming out from the industries had grown to a significant level and it has been discharged to rivers, canals etc thereby it affect the aquatic organisms. ${ }^{4}$ To remove such heavy metals in water is most crucial for several researchers to save the aquatic organisms and also to use water effectively. Several metals include, including lead, copper and cadmium are more dangerous to the environment coming out from the industries creates more stress to the aquatic and human health. ${ }^{5}$ The consumption of such heavy metals directly or indirectly affects the neurological system of the brain, reproduction system, liver and so on. The maximum permissible limit of these pollutants in water stated by the environmental protection agency was $1.3 \mathrm{ppm}$ for copper, $0.1 \mathrm{ppm}$ for lead and $0.005 \mathrm{ppm}$ for cadmium which determines the need for removal of such heavy metals in waste water. ${ }^{6,7}$ Several researchers were tried to incorporate natural materials to remove heavy metals in water utilizing the adsorption process. The utilization of natural materials makes the entire system economical and feasible. ${ }^{8-}$ 10

To avoid water stress among human beings potential utilization of greywater is a viable option. Proper treatment of greywater will satisfy the water demands of animals and humans. The effluent coming out from households usually contains organic materials and it should be screened out for the better treatment of grey water. ${ }^{11}$ Almost $40 \%$ of the human water needs should be satisfied by the potential reuse of greywater. The dust particles present in the clothes and chemical components in the washing powder contribute to the total suspended solids composition of greywater. 
Heavy metals present in the wastewater effluents from textile industries and other chemical industries create several environmental threats. These effluents contaminate the soil and accumulate into the roots of the plants thereby the consumption of such vegetables derived from the plants grown on the contaminated soil severely damages the human organs. ${ }^{12,13}$ The basic requirement for any living organism is water. Availability of freshwater is becoming crucial now a day due to the rapid population. Urban and industrial activities led to the rise of heavy metal pollution. ${ }^{14}$ Pollution in water due to the accumulation of heavy metals is considered to be a serious threat to the environment. These heavy metals are non-biodegradable and pose severe problems to human beings. The most widely used heavy metal in the industry is copper(II) is considered to be a widely used heavy metal in most industries which includes paper board, fertilizers, paints etc. The discharge coming out from the industries usually contains a considerable amount of heavy metals which deposits into the soil and other water streams. ${ }^{15-18}$ Consumption of such water and plants that grow on heavy metal deposited soil causes several health issues to human beings. Treatment of pollutants in water is very difficult because people do not have the necessary resources to treat the polluted water. ${ }^{19-21}$ As per the survey of the World Health Organization (WHO), people spent almost 30-40mins/day collecting water sources and the inability of people to collect water from proper sources causes several diseases. Most people die every year with diarrhea which accounts for about a 1.5 million people per year. ${ }^{22}$

Several studies have been conducted on the removal of heavy metals from water. Modern many methods are used to remove heavy metals in water such as electrocoagulation, activated carbon and modified adsorbents. ${ }^{23,24}$ Such methods are uneconomical due to their operating costs. Several conventional methods were used to remove heavy metals in the effluents. Such methods have their drawbacks due to their high operational cost, maintenance cost and disposal of sludge. The utilization of natural waste materials has resolved the drawbacks of conventional methods. Naturally, available waste materials were used effectively in various fields i.e. in producing sustainable building material to reduce the carbon dioxide emission levels in the atmosphere. Several studies were conducted to remove the toxic metals using naturally available agricultural wastes. ${ }^{25-27}$

In this study, moringa seed powder was used to remove the heavy metals in the solution using the adsorption process. The effect of $\mathrm{pH}$ and temperature on the adsorption efficiency of moringa seed was evaluated. In addition to the adsorption process, the removal efficiency of sulphate, chloride and other compounds in greywater were evaluated using moringa seed powder. The initial concentration of $\mathrm{pH}$, COD, BOD, TSS, and TDS, sulphate, chloride and grease found in influent water was calculated in the laboratory. The experimental setup consists of sand, waste material powder and activated carbon.

\section{MATERIAL PREPARATION}

Moringa seed is a naturally available material collected from the local market in Chennai, India. Moringa seeds were collected and washed in clear water to remove the impurities and allowed to dry in the open air for 24 hours. Further seeds were kept in an oven at $30^{\circ} \mathrm{c}$ for 7 hours to remove the surface moisture and then seeds were grounded finely and sieved through a 100 micron sieve. Greywater collected from the household is allowed to settle for 24hours. The experimental setup was shown in Fig.-4.

\section{FTIR Analysis}

\section{RESULTS AND DISCUSSION}

The FTIR spectra of moringa seeds after and before adsorption of chromium ions as shown in Fig.-1. The presence of lignin, carbohydrates and some other proteins adsorbs metal ions in wastewater and due to this a heavy band at $3218 \mathrm{~cm}^{-1}$ is originated. The occurrence of nitrogen hydrogen bond by vibrational extension, present in $\mathrm{NH}_{4}$ groups is mainly due to the presence of protein in moringa seeds. Carbon hydrogen vibrational extension occurs at a frequency of 2911 and $2834 \mathrm{~cm}^{-1}$ mainly due to the presence of methyl groups in the fats and alkaline group. The carboxyl and carbon-oxygen groups manifest at a frequency of $1673 \mathrm{~cm}^{-1}$.

The FTIR spectra of Moringa after adsorption is shown in Fig.-1. From the figure it is evident that the frequency at $3218 \mathrm{~cm}^{-1}$ has been reduced to $3118 \mathrm{~cm}^{-1}$ due to the adsorption of chromium ions. The frequencies at 2911 and $2834 \mathrm{~cm}^{-1}$ have been shifted to 2978 and $2894 \mathrm{~cm}^{-1}$ respectively 
RASĀYAN J. Chem.

Vol. 14 | No. 3 |2024-2030| July - September | 2021
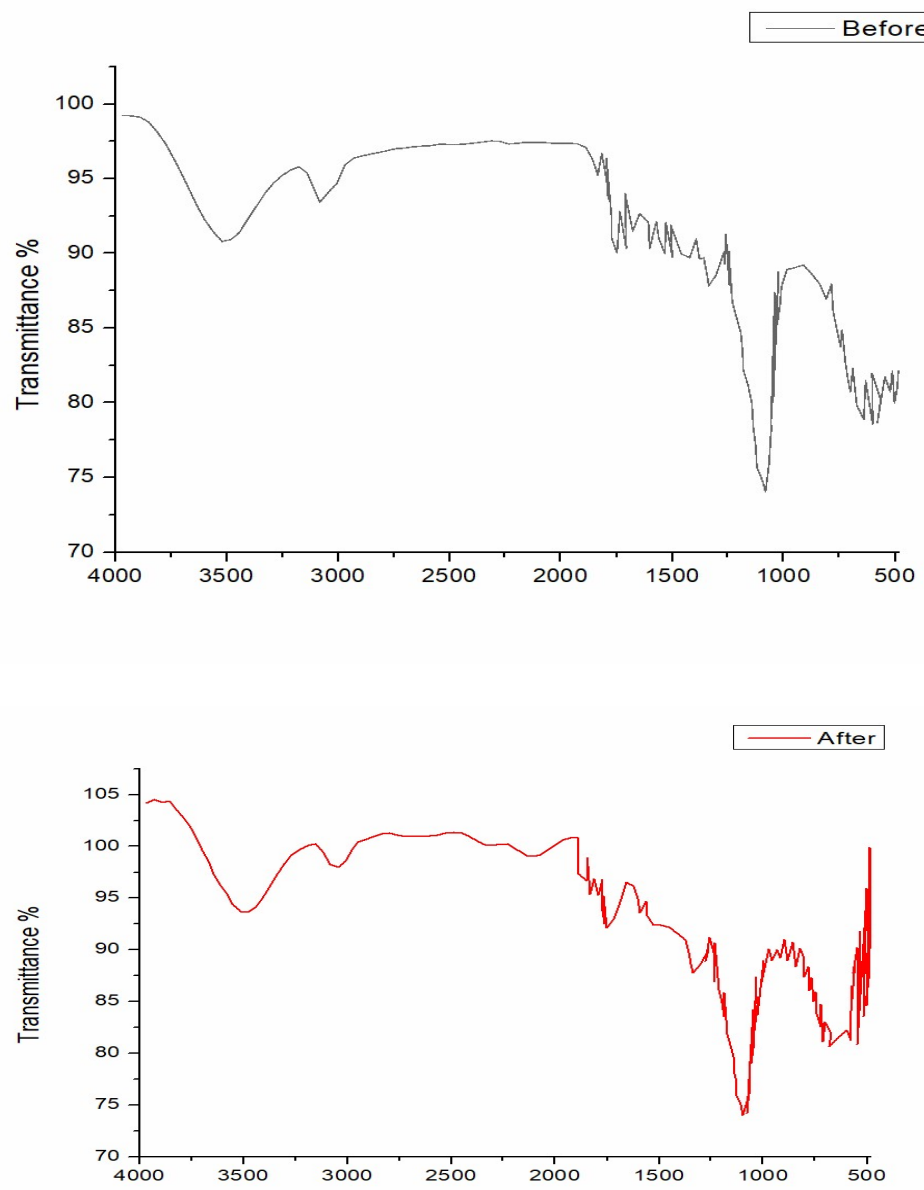

\section{Effect of pH}

Fig.-1: Before ad after adsorption of chromium ions

The dependency on the adsorption of heavy metals is mainly based on the acidity of the solution. At lower $\mathrm{pH}$ the efficiency of adsorption is higher as shown in Fig.-2. The adsorption of chromium metal was high in the $\mathrm{pH}$ range between 2 to 4 . When the $\mathrm{pH}$ reaches the value of 4 , maximum adsorption of heavy metal was observed. This is mainly due to an increase in proton levels and attacks the binding locations on the layer of adsorbent. The activated proton site was not efficient to bind the heavy metal atoms, causes free ions to remains in the solution. As the initial concentration of $\mathrm{pH}$ was at 3 , the chromium ions get dissolved due to the presence of concentrated ions in the solution. From this study, the optimum $\mathrm{pH}$ to remove the chromium ions in the solution was found to be 4 .

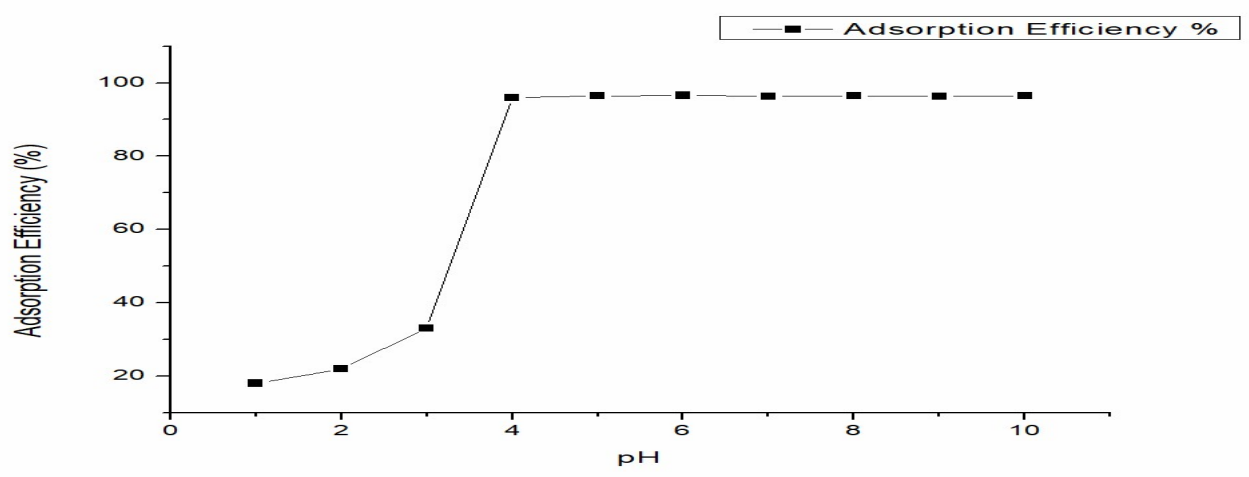

Fig.-2: Effect of $\mathrm{pH}$ on adsorption efficiency 
RASĀYAN J. Chem.

Vol. 14 | No. 3 |2024-2030| July - September | 2021

\section{Effect of Temperature}

From the Fig.-3, it is evident that at room temperature the adsorption efficiency was higher. In the temperature range between 18 to 25 , the efficiency of moringa seed powder showed maximum value. It is mainly attributed due to hydroxyl ions reactions with a solution at room temperature. At higher temperatures, the ions in the solutions lost their binding capacity and flow freely. From this study, it is found the optimum temperature to maximum adsorption of heavy metals in the solution was found to be $20-23^{\circ} \mathrm{C}$.

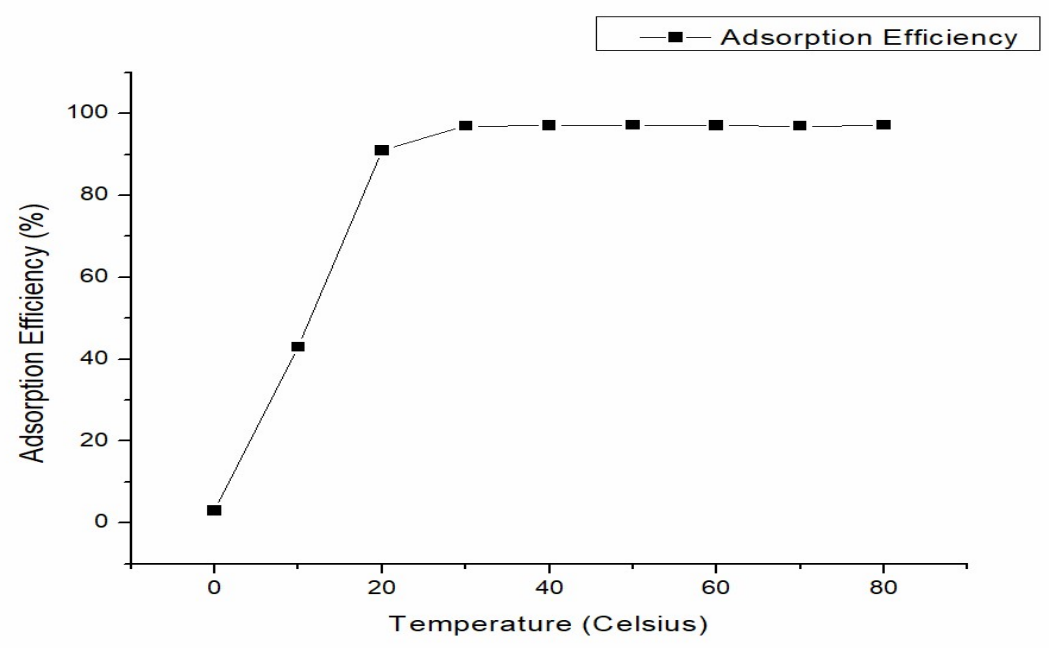

Fig.-3: Effect of Temperature on Adsorption Efficiency

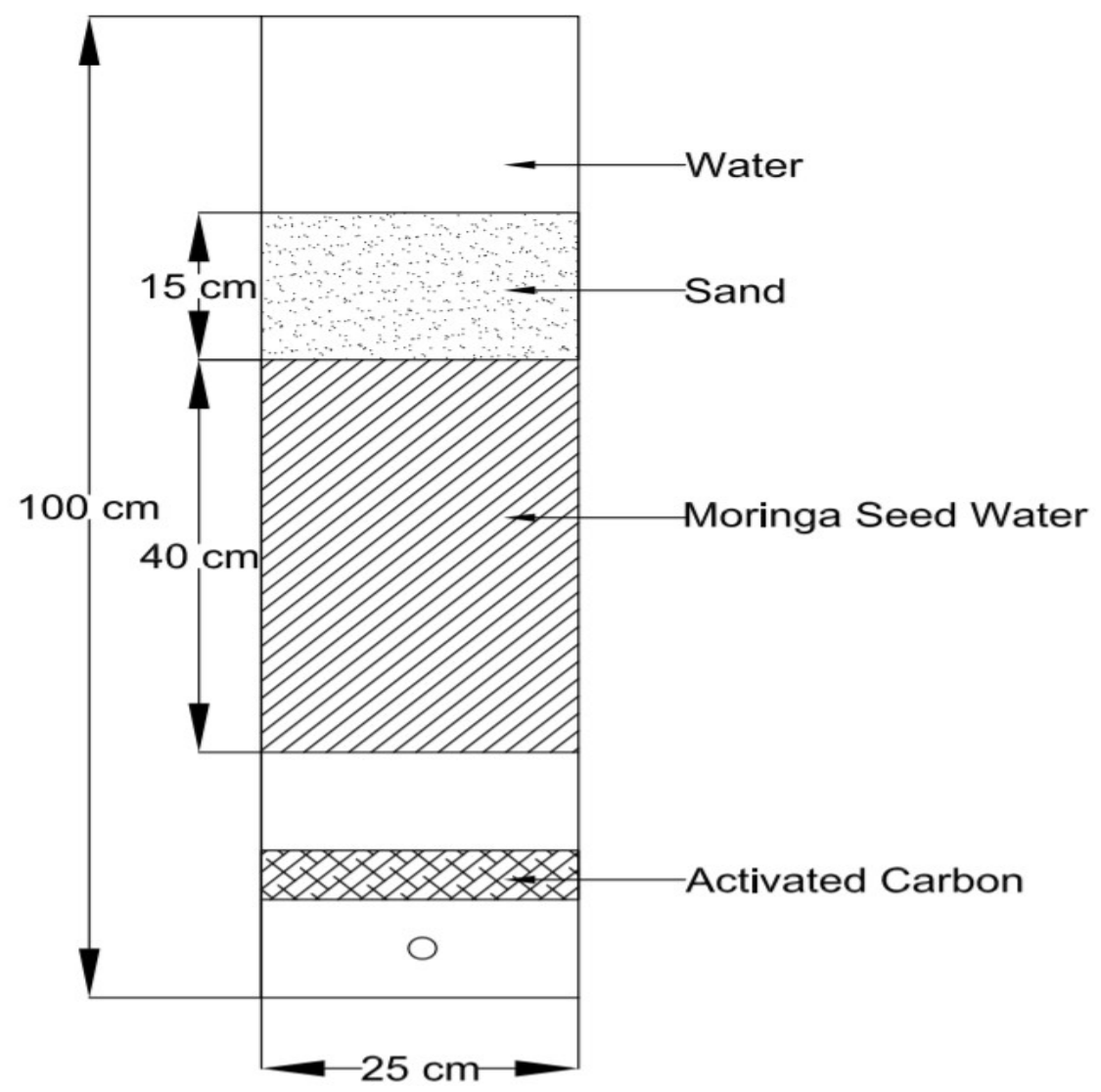

Fig.-4: Experimental Setup of the Treatment Process 
RASĀYAN J. Chem.

Vol. 14 | No. 3 |2024-2030| July - September | 2021

\section{Water Quality Parameters \\ pH}

As per WHO and TNPCB (Tamilnadu pollution control Board), the $\mathrm{pH}$ of the water should be in a range of 5-9 and 6.5-9 respectively. $\mathrm{pH}$ of influent greywater was in the range of WHO and TNPCB standards and it was found to be 7.98. Since the $\mathrm{pH}$ of water had no influential role but it is responsible for the other chemical reactions in water. The average $\mathrm{pH}$ of water after treating with natural waste materials was found to be 7.64 . The final $\mathrm{pH}$ of water after treatment was $4.23 \%$ lower than influent water.

\section{Sulfate}

The initial concentration of sulphate in greywater was found to be $375 \mathrm{mg} / 1$. After treating the water with natural waste materials, the concentration of sulphates in water was reduced to $275 \mathrm{mg} / 1,204 \mathrm{mg} / 1$ and 120 $\mathrm{mg} / \mathrm{l}$ on day 1 , day 4 and day 12 treatment respectively. The average concentration of sulphate in water was calculated as $199.7 \mathrm{mg} / 1$ and removal efficiency of $46.7 \%$.

\section{Chloride}

The initial concentration of chloride was $2412 \mathrm{mg} / \mathrm{l}$ which is far above the WHO and TNPCB standards. The effluent coming out from the experimental setup was measured at day1, day 4 and day12 as 1523 , $943,525 \mathrm{mg} / 1$ respectively satisfy both WHO and TNPCB standards. The removal efficiency of chloride concentration was calculated as $58 \%$.

\section{TDS and TSS}

The initial TDS level of greywater is far below the TNPCB standards and it was measured as $1372 \mathrm{mg} / \mathrm{l}$. After treating greywater, the TDS level was reduced to 927,891 and $745 \mathrm{mg} / 1$ at day 1 , day 4 and day 12 respectively. The removal efficiency of TDS in greywater after treatment was calculated as $37.7 \%$ shown in Fig-5. The results of TSS were quite similar to that of TDS values. The initial concentration of TSS level of greywater was found to be $145 \mathrm{mg} / 1$, which is far above the WHO and TNPCB standards. The permissible limit of TSS in water recommended by WHO and TNPCB were 35 and 50mg/l respectively. After treating the water with natural materials, the concentration of TSS in water was reduced to 74,41 and $20 \mathrm{mg} / 1$ at day 1 , day4 and day 12 respectively.

\section{Total Hardness}

The presence of magnesium and calcium ions present in the water makes the water hard. Due to the presence of calcium and magnesium ions the boiling point of water increases and forms a sticky layer on the vessels. The total hardness of the water in greywater was found to be $1572 \mathrm{mg} / \mathrm{l}$. After being subjected to treatment, the hardness of water reduces to $1024 \mathrm{mg} / 1,726 \mathrm{mg} / 1$ and $650 \mathrm{mg} / \mathrm{l}$ at day 1 , day 4 and day 12 respectively. The average hardness of water was calculated as $800 \mathrm{mg} / 1$ and removal efficiency was found to be $49 \%$.

\section{BOD}

The Oxygen required by the microorganisms to decompose and consume the organic matter present in the water is referred to as biological oxygen demand. The BOD of water coming out from the household was taken and calculated as $32 \mathrm{mg} / 1$. After being subjected to the treatment process, the BOD value gradually reduces from day1 to day 12 . The removal efficiency of BOD was found to be $52 \%$.

\section{COD}

The oxygen required in water to convert the organic matter into the inorganic matter is referred to as Chemical oxygen demand. Reduction in dissolved oxygen level is mainly attributed to COD and BOD concentration. A higher amount of BOD and COD concentration reduces the dissolved oxygen level in the water, thereby it affects the life of aquatic organisms. The initial concentration of COD level was calculated as $173 \mathrm{mg} / \mathrm{l}$ and the value is far higher than WHO standards. The value of COD in water reduces when subjected to treatment using natural wastes. The removal efficiency of COD in greywater after the treatment process was measured as $47 \%$. 
RASĀYAN J. Chem.

Vol. 14 | No. 3 |2024-2030| July - September | 2021

\section{Oil and Grease}

The presence of Oil and grease in water is considered to be an important parameter while assessing the quality of water. The initial concentration of oil and grease in water was measured as $7.1 \mathrm{mg} / \mathrm{l}$ shown in Fig-5. After being subjected to treatment, the concentration of oil and grease reduces gradually and the average concentration of oil and grease in water was found to be $2.8 \mathrm{mg} / \mathrm{l}$. The Removal Efficiency of oil and grease in water was measured as $61 \%$

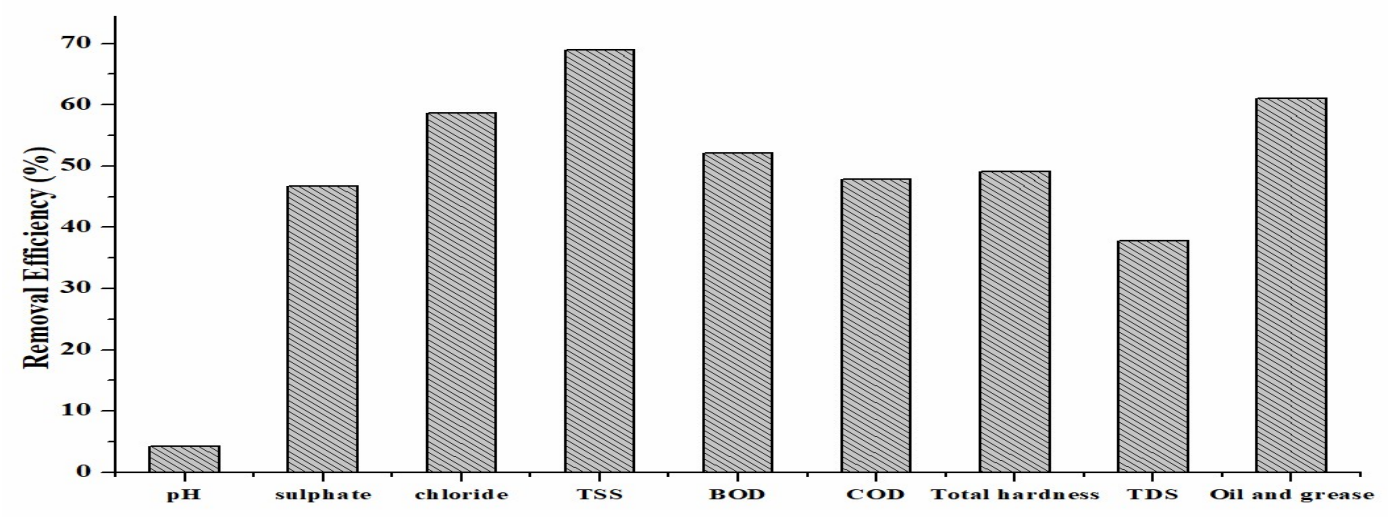

Fig.-5: Removal Efficiency of Water Quality Parameters

\section{CONCLUSION}

Moringa seed powder showed better performance on the removal of chromium ions in the solution. The optimum $\mathrm{pH}$ and temperature on removing the heavy metals in the solution were found to be 4 and $22^{\circ} \mathrm{C}$ respectively. The initial concentration and the final concentration of greywater after treatment were collected and tested in the laboratory. The samples were compared with TNPCB and WHO standards. The initial concentration $\mathrm{pH}$, TDS, Total hardness, oil and grease show the value less than WHO and TNPCB standards. So a reduction in the above values had not shown much impact on the quality of water. The other parameters in water like sulphate, chloride, TSS, BOD and COD had values higher than WHO and TNPCB standards. After treatment, the removal efficiency of sulphate, chloride, TSS, BOD and COD reduces by $46.7,58,68,52$ and $47 \%$ respectively. From this study, it was found that utilization of natural waste material in wastewater improves the quality of water and it can be used for lawns, groundwater recharge and other irrigation practices.

\section{REFERENCES}

1. Mahalakshmi, Mathivanan and S.E. Saranaathan, Rasayan Journal of Chemistry, 11(2), 877(2018), http://dx.doi.org/10.31788/RJC.2018.1122086

2. Al-Qodah, M. Al-Shannag, Separation Science and Technology, 52(17), 2649(2017), https://doi.org/10.1080/01496395.2017.1373677

3. A. Ahmad, Z.A. Ghazi, M. Saeed, M. Ilyas, R. Ahmad, A.M. Khattaka, New Journal of Chemistry, 41, 10799(2017), https://doi.org/10.1039/C8NJ01778F

4. S. Babel, T.A. Kurniawan, Journal of Hazardous Materials, 97(1-3), 219(2003), https://doi.org/10.1016/s0304-3894(02)00263-7

5. S. Ramesh, J. S. Sudarsan and M. Jothilingam, Rasayan Journal of Chemistry, 9(3), 325(2016),

6. A. Bhowmik, A. Alamdar, I. Katsoyiannis, H. Shen, N. Ali, S. Ali, H. Bokhari, R. Schäfer, S. Musst,
A. Eqani,
Science
of Total
Environment,
538, 306(2015), https://doi.org/10.1016/j.scitotenv.2015.08.069

7. S. Gholap, S. Chaskar and C. Gill, Rasayan Journal of Chemistry, 1, 330(2008).

8. D. Bozic, V. Stankovic, M. Gorgievski, G. Bogdanovic, R. Kovacevic, Journal of Hazardous Materials,171(1-3), 684(2009). https://doi.org/10.1016/j.jhazmat.2009.06.055

9. K. Kirthika, T. R. Praveenkumar, International Journal of ChemTech Research, 8(7), 434(2015). 
RASĀYAN J. Chem.

Vol. 14 | No. 3 |2024-2030| July - September | 2021

10. H. Chen, J. Zhao, G. Dai, J. Wu, H. Yan, $\quad$ Desalination, $\quad 262, \quad 174(2010)$ https://doi.org/10.3303/CET1437119

11. M. Dakiky, M. Khamis, A. Manassra, M. Mer'eb, Advance Environmental Research, 6,533(2002) https://doi.org/10.1016/S1093-0191(01)00079-X

12. S. Sharma, S. Gangal and A. Rauf, Rasayan Journal of Chemistry,1, 693(2008).

13. C. Sumithra, and S. Karthikeyan, Rasayan Journal of Chemistry, 7, 149(2014).

14. Derakhshan Nejad, M.C. Jung, K.H. Kim, Environmental Geochemistry and Health, 40(3) ,927(2018) https://doi.org/10.1007/s10653-017-9964-Z

15. S. Karthikeyan, K. Sakthivel and C. Kannan, Rasayan Journal of Chemistry, 4, 519(2011).

16. C. Sudheesh, T. R. Praveenkumar, S. Sasi Kumar, International Journal of ChemTech Research, 8(4), 2219(2015).

17. B. Sivakumar, P. Nithya, S. Karthikeyan and C. Kannan, Rasayan Journal of Chemistry, 7, 161(2014).

18. H. Agrawal, C. Shee and A. K. Sharma, Research Journal of Agriculture and Biological Sciences, 3(5), 418(2007).

19. R. Pitt, S. Clark, and R. Field, Urban Water, 1, 217(1999), https://doi.org/10.12691/ajwr-6-3-1

20. Y. R. Ronzhya, T. R. Praveenkumar, International Journal of ChemTech Research, 8(2), 836(2015).

21. M. Ajmal, R.A. Rao, R. Ahmad, J. Ahmad, Journal of Hazardous Materials, 79(1-2),117(2000), https://doi.org/10.1016/S0304-3894(00)00234-X

22. Y. Ge, Z. Li, ACS Sustainable Chemistry and Engineering, $6,7181(2018)$, https://doi.org/10.1021/acsami.5b03994

23. X. Guo, S. Zhang, X.Q. Shan, Journal of Hazardous Materials,151(1),134(2008), https://doi.org/10.1016/j.jhazmat.2007.05.065

24. S. Herat, P. Agamuthu, Waste Managament Research, 30(11), 1113(2012), https://doi.org/10.1177/0734242X12453378

25. M. Yang, Z. Guo, Y. Deng, X. Xing, K. Qiu, J. Long, J. Li, International Journal of Mineral Processing, 102, 112(2012).

26. P. Eshanthini, V. Chiristina Mary and M. Kalaivani, Pollution Research, 36(2), 253(2017).

27. P. Eshanthini and T. K. Padmini, International Journal of PharmTech Research, 8(10),171(2015).

[RJC-6129/2020] 